\title{
PENGONTROLAN ROBOT HUMANOID MENGGUNAKAN METODE SPEECH RECOGNATION BERBASIS MIKROKONTROLLER RASPBERRY PI
}

\author{
Gun Gun Maulana ${ }^{1}$, Adhitya Sumardi $\mathrm{S}^{2}$ \\ ${ }^{12}$ Teknik Otomasi Manufaktur dan Mekatronika, Politeknik Manufaktur Bandung, \\ Jl. Kanayakan no 21 Bandung, Indonesia \\ I'gungun@polman-bandung.ac.id, ${ }^{2}$ adhitya@polman-bandung.ac.id
}

\begin{abstract}
Abstrak-Robot adalah mesin yang dirancang untuk dapat melakukan tugas tertentu dan dapat melakukan multitasking berdasarkan pemrograman yang dilakukan oleh user. Namun kendala saat ini adalah user mengalami kesulitan dalam mengendalikan robot karena harus memahami Bahasa pemrograman yang komplek serta penggunaan kabel yang rumit saat pemasangannya, oleh karena itu penulis menyajikan system pengontrollan menggunakan metode speech recognition dan skeleton tracking menggunakan sensor Kinect agar robot dapat diperintah mengikuti suara dan gerakan manusia tanpa harus menguasai Bahasa pemrograman, agar pengontrollan lebih fleksible penulis mengusulkan system pengontrolan robot yang dikendalikan dari jarak jauh melalui jaringan Wi-Fi, dengan menggunakan raspberryPI sebagai mikrokontrollernya, dimana data inputan dari user akan diproses oleh visual studio untuk mendapatkan informasi suara dan sudut dari user, kemudian informasi tersebut dikirimkan ke mikrokoonttoller melalui jaringan wifi untuk menggerakan robot tersebut. Hasil percobaan menunjukkan bahwa robot dapat dikendalikan dari jarak jauh melalui suara dan gerakan manusia dengan cukup akura yaitu sebesar $97.2 \% t$.
\end{abstract}

Keywords - Speech Recognition, Skeleton Tracking. Robot Humanoid, Kinect, WiFi

\section{Pendahuluan}

Baru-baru ini, perkembangan teknologi robot semakin cepat dan menjadi hal yang umum pada berbagai bidang. [1], robotika yang marak dikembangkan yaitu robot humanoid mengingat banyak sekali manfaat yang dapat digunakan dalam aplikasi robot ini [2], Robot dapat digunakan untuk melakukan tugas - tugas, khususnya di tempat berbahaya, untuk mengumpulkan data-data yang diperlukan dan mengirimkannya kepada para pengguna yang terletak jauh dari tempat tersebut [3], Saat ini robot humanoid dan subsistem robot sudah digunakan secara luas, jadi ini adalah hal yang bagus untuk kita dukung [4],

Namun kendala saat ini adalah user mengalami kesulitan dalam mengendalikan robot tersebut karena mereka harus memahami Bahasa pemrograman yang komplek serta penggunaan kabel yang rumit saat pemasangannya [5], oleh karena itu penulis menyajikan sebuah system pengontrollan menggunakan metode skeleton tracking dan pengenalan suara menggunakan sensor Kinect agar robot dapat diperintah mengikuti gerakan manusia tanpa harus menguasai Bahasa pemrograman, agar pengontrollan lebih fleksible penulis mengusulkan system pengontrolan robot yang dikendalikan dari jarak jauh melalui jaringan Wi-Fi, dengan menggunakan raspberryPI sebagai mikrokontrollernya. Dimana suara manusia dijadikan sebagai setpoin untuk menggerakan robot, Teknologi pengenalan suara telah banyak dikembangkan Salah satunya adalah Kinect. Kinect telah mampu mengenali beberapa bahasa, tetapi tidak dengan bahasa Indonesia [6], Kamera Kinect dapat digunakan untuk menangkap gambar tubuh dan suara manusia yang sering digunakan dalam bermain video game [7], Microsoft Kinect sensor terkenal karena keefektifannya dalam gesture dan speech recognition yang dapat digunakan untuk penginderaan jarak jauh dan sistem control [8], Kinect merupakan video recognition sensor yang terdiri atas 3 kamera dan 4 mic-array, sehingga memungkinkan user untuk berinteraksi dengan game Xbox 360 tanpa menggunakan joystik [9], untuk selanjutnya suara yang diterima oleh Kinect kemudian dikirimkan ke visual studio untuk diolah menjadi sinyal digital untuk kemudian dikirimkan ke database, dimana database dalam penelitian ini menggunakan firebase. Firebase adalah database real time yang menggunakan basis data NO-SQL yang artinya data tidak disimpan dalam format tabel SQL tetapi dalam format path tree. Dengan fitur realtime dari Firebase Real time Database, aplikasi sisi pengguna tidak perlu meminta pembaruan data lagi karena akan sinkronisasi secara otomatis [10] untuk selanjutnya file di firebase akan dikirimkan ke raspberry pi, Raspberry Pi adalah papan komputer yang kecil, kuat, murah dan beroperasi dengan cara yang sama seperti PC standar, membutuhkan keyboard untuk entri perintah, unit tampilan dan catu daya.[11], Pertimbangan menggunakan Raspberry Pi dikarenakan papan ini menyediakan konfigurasi yang sedikit atau sedikit lebih banyak dibandingkan dengan 
mikrokontroller lain [12], setelah data diterima oleh raspberry pi kemudian akan di kirimkan ke SSC-32. SSC-32 adalah kontroller servo yang menyediakan antarmuka perangkat keras antara komputer dan lengan robot. Ini memiliki resolusi waktu $1 \mu$ s untuk penentuan posisi yang akurat dan kontrol motor dc ke menghasilkan gerakan yang sangat halus [13] Dengan dibuatnya system ini diharapkan proses pengendalian robot akan menjadi lebih mudah dengan memanfaatkan perangkat Kinect sebagai sensor yang menerima inputan suara untuk selanjutnya diolah menjadi perintah untuk menggerakan robot manusia.

\section{METODE PENELITIAN}

\section{A. Gambaran Umum Sistem}

Pada Penelitian ini, arsitektur sistem dalam pengendalian robot humanoid jenis BRAT menggunakan mtode pengenalan suara atau speech recognition yang berbasis internet dengan visual studio sebagai antar muka dalam memonitor jalannya sistem yang bekerja. Berikut penjelasan secara umum sistem dapat dilihat pada gambar1. di bawah ini.

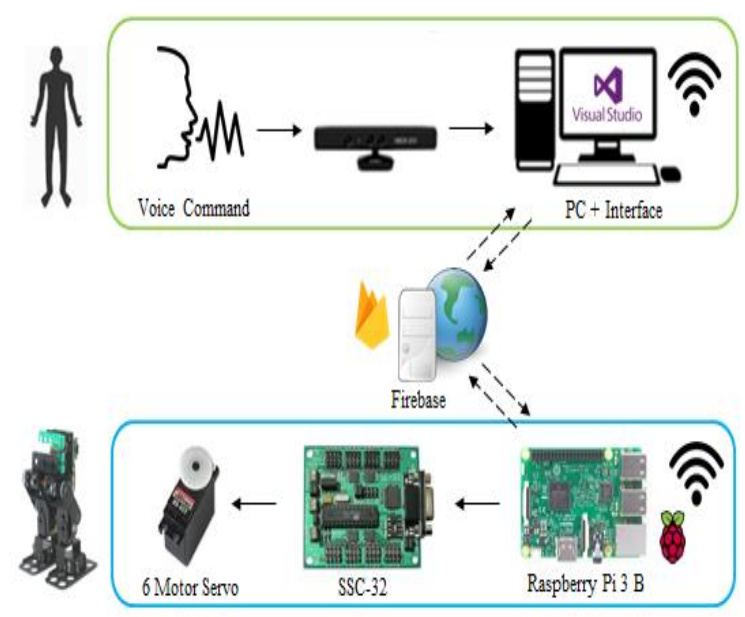

Gbr 1. Gambaran Umum Sistem.

Secara umum, sistem yang akan dibuat dapat dijelaskan oleh gambar 1. di atas, dimana pengguna atau user memberikan input berupa perintah suara yang kemudian ditangkap oleh mikrofon yang terdapat pada perangkat kinect. Berdasarkan prinsip kerjanya, perangkat kinect dapat memperkuat sinyal suara yang tertangkap. Setelah sinyal dari suara diubah menjadi sebuah sinyal digital, maka kemudian sinyal tersebut akan diprogram menjadi sebuah data pada perangkat lunak Visual Studio, dimana data tersebut berisikan perintah yang telah didefinisikan sebelumnya berdasarkan input perintah suara apa yang telah tertangkap, kemudian data tersebut dikirimkan dari perangkat lunak visual studio ke sebuah database webserver yang bernama firebase dengan bantuan koneksi internet. Setelah data tersebut berhasil terkirim pada database maka selanjutnya data yang terdapat pada database tersebut akan diambil alih oleh perangkat raspberry pi dengan koneksi internet yang terdapat pada robot untuk diolah lebih lanjut, dimana data perintah yang diterima akan diolah dan dieksekusi menjadi sebuah program pergerakan motor servo melalui sebuah modul SSC-32 servo controller dengan menggunakan protokol komunikasi serial. Ketika robot berhasil melakukan suatu pergerakan sesuai perintah yang masuk, maka perangkat raspberry pi akan mengirim sebuah data status ke database, yang kemudian data status tersebut akan diambil alih oleh antar muka visual studio sebagai indikator jalannya sistem.

\section{B. Domain Rancangan Spesifik}

Domain rancangan spesifik merupakan tahap dimana tiap-tiap pembuatan domain yang menyusun prototipe ini dijelaskan secara terpisah. Menurut standar VDI 2206, pada sistem mekatronika ada tiga domain utama yang menyusun suatu produk [15]. Domain-domain tersebut adalah domain elektrik, domain mekanik, dan domain kontrol / informatik.

1). Perancangan Domain Mekanik : Mengingat pada penelitian ini hanya difokuskan pada sistem pengendalian robot menggunakan metode speech recognition yang berbasis internet tanpa ada fungsi autonomous atau behaviour maka perancangan robot controller hanya sebatas menjalankan perintah langsung dengan gerakan sederhana maka pembuatan robot dibuat sesederhana mungkin. Perangkat mekanik pada penelitian ini yaitu robot, dimana robot dalam hal ini menjadi objek yang dikendalikan sistem. Sistem mekanik robot yang dibangun terdiri dari motor servo sebagai joint penghasil sudut, dan untuk linknya terdiri plat baja profile. Bahan yang digunakan link adalah alumunium karena kokoh dan memiliki ketahanan terhadap karat, selain itu bahan ini ringan sehingga tidak terlalu membebani motor servo seperti terlihat pada gambar 2 dan 3 dibawah ini.
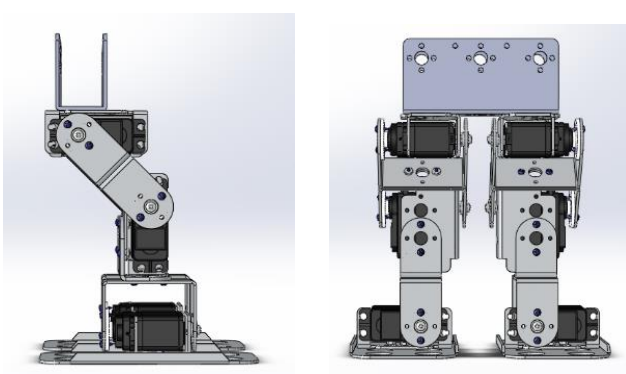

Gbr 2. Rancangan Mekanik

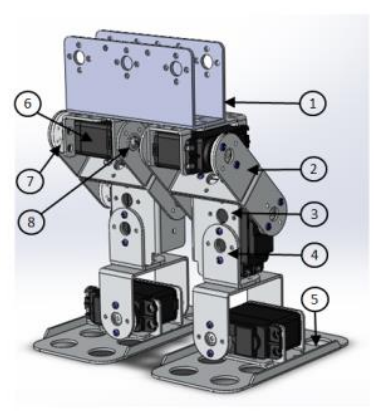




\begin{tabular}{|c|l|c|c|}
\hline No. & Nama Komponen & Dimensi (mm) & Jumlah (pcs) \\
\hline 1 & U Shape & $55.8 \times 43.5 \times 2$ & 6 \\
\hline 2 & Mount Servo & $58 \times 37 \times 2$ & 6 \\
\hline 3 & L Shape & $37.3 \times 29.3 \times 2$ & 2 \\
\hline 4 & U Bridge & $90.5 \times 43.5 \times 2$ & 1 \\
\hline 5 & Foot & $123.4 \times 63.3 \times 2$ & 2 \\
\hline 6 & Servo & $40.4 \times 19.5 \times 36.6$ & 6 \\
\hline 7 & Bearing & $8 \times 3 \times 4$ & 6 \\
\hline 8 & Horn & $20 \times 3 \times 2$ & 6 \\
\hline
\end{tabular}

Gbr 3. Rancangan mekanik tampak keseluruhan

2). Perancangan Domain Elektrik: Gambar 4. merupakan gambar skematik dari Raspberry Pi 3 B yang berfungsi untuk mengolah data masukan dari database dalam sistem ini.

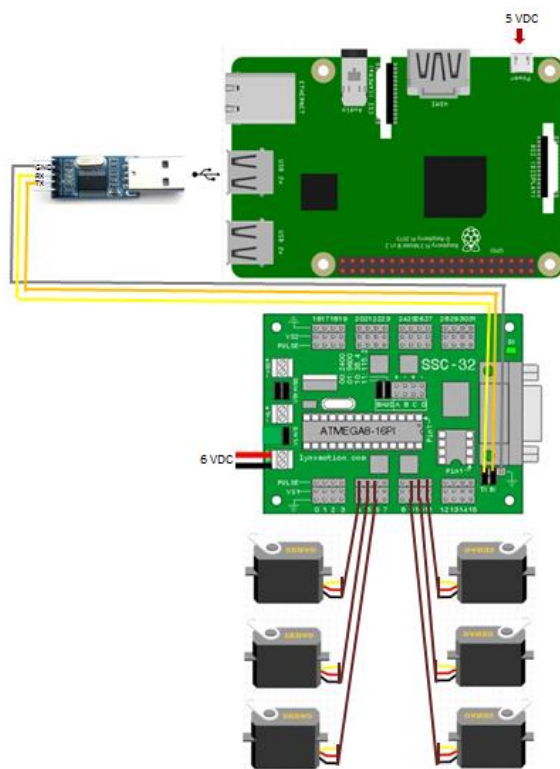

Gbr 4. Skematik Rangkaian Sistem Elektrik Secara Keseluruhan

Pada gambar 4. Diatas Raspberry Pi terhubung ke servo controller SSC-32 dengan bantuan modul USB TTL PL2303 untuk bisa melakukan komunikasi serial untuk mengirim data perintah pergerakan servo. Subproses ini merupakan proses instalasi sistem dimana terdapat hubungan-hubungan yang salin terjalin dalam suatu domain. Tahapan ini meliputi instalasi perangkat kinect, Raspberry $\mathrm{Pi} 3 \mathrm{~B}$, PL2303 USB to TTL dengan perangkat keras mekanik, instalasi Servo Controller SSC-32 pada robot biped BRAT beserta wiring pengalamatan tiap-tiap servo. Selanjutnya instalasi program kendali speech recognition dan pergerakan dari robot humanoid BRAT.
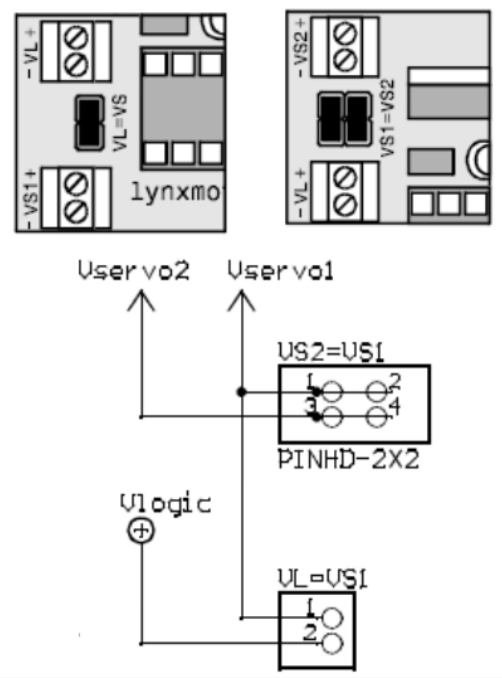

Gbr 5. Skematik Rangkaian Sistem elektrik[13]

Secara Keseluruhan Pada gambar 5. terdapat skematik rangkaian untuk power supply pada modul SSC32 dimana terdapat 3 terminal yaitu VL, VS1 dan VS2. Dimana pada masing-masing terminal mempunyai tegangan yang berbeda-beda dalam kebutuhannya, untuk VS tegangan yang diizinkan yaitu 6-9 VDC sedangkan untuk VS1 dan VS2 yaitu masing-masing 6 VDC. Namun pada pengaplikasianya modul SSC32 ini dapat disiasati dengan menjumper antar terminal dengan catatan masih dalam batas tegangan yang diizinkan. Dengan kondisi yang demikian maka kita bisa memberi masukan power sebesar 6 VDC pada salah satu dari ke tiga terminal tersebut untuk menjalankan semua fungsi pada modul SSC32. Sedangkanuntuk bagian pengolah data masukan terdapat instalasi berupa kinect dan PC sebagai pengolah data masukan untuk setiap perintah yang masuk.

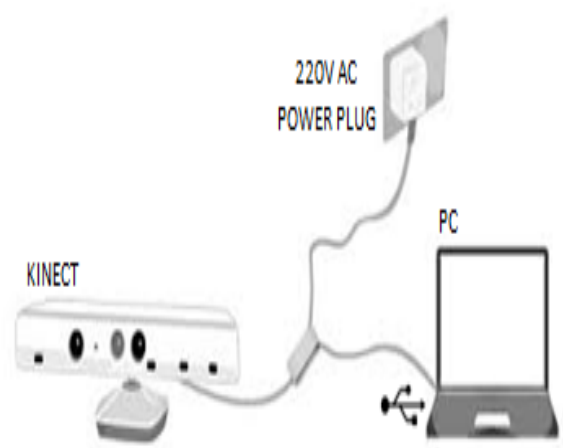

Gbr 1. Rangkaian Penggerak Motor DC[16]

Pada gambar 6. Diatas Dengan mengunakan power $220 \mathrm{~V}$ AC rangkaian Kinect dengan PC melalui sambungan USB digunakan untuk meneruskan sinyal analog dari gelombang suara menjadi sebuah masukan sinyal digital menuju ke antar muka visual studio di PC untuk diolah lebih lanjut. Pada kerjanya rangkaian ini dibuat agar lebih fleksibel dalam pengambilan/ 
penangkapan suara dari user dimana user tidak perlu melakukan mobilitas berlebih dalam melakukan pengendalian robot yaitu cukup dengan memberikan perintah suara dengan berada dalam area kerja kinect tanpa dibatasi dengan robot yang.

\section{3). Perancangan Domain Kontrol /}

Page| 27 informatic :Tahap selanjutnya ialah membuat program skeletal tracking menggunakan Microsoft Kinect yang berperan sebagai transducer, untuk menghasilkan data gestur dari pengguna. Gambar 7. di bawah ini menunjukan titik yang dapat dideteksi oleh kinect beserta sumbu kartesian referensi. Pada perancangan domain kontrol, sistem yang akan dirancang menggunakan mikrokontroler sebagai pengendali. Pemrograman dilakukan dengan menggunakan Python IDE pada raspberry pi dan Microsoft Visual Studio pada PC. Perancangan domain kontrol sistem ini terdiri dari beberapa subsistem program yaitu, program untuk konversi sinyal analog dari sebuah gelombang suara yang masuk menjadi sebuah data digital, program antarmuka, dan komunikasi database berbasis internet sebagai program utamanya. Secara garis besar, diagram alir sistem pengendalian dan pemantauan robot humanoid diawali dengan pemberian sumber listrik AC pada perangkat kontrol dan sumber listrik DC pada perangkat robot. Pada awal pengoperasian, pengguna cukup mengaktifkan masing masing perangkat yang saling berkaitan sebagai inisialisasi awal sistem. Adapun diagram alir sistem secara umum dapat dilihat pada gambar 7 dibawah ini.

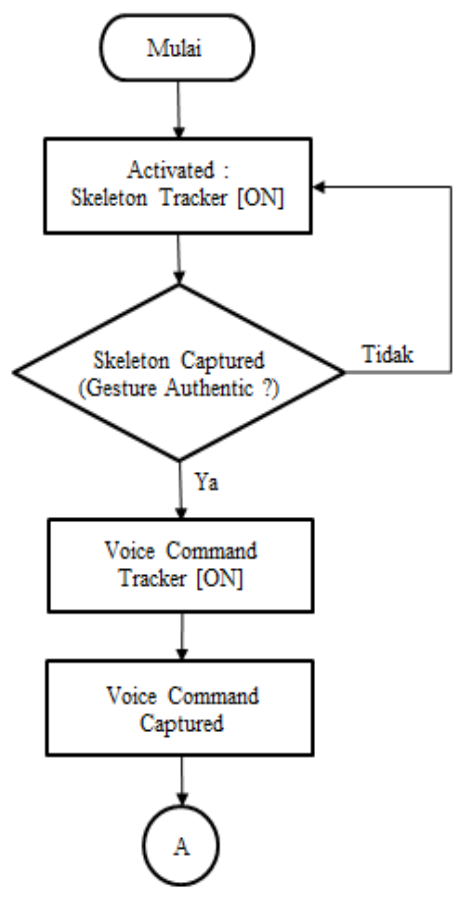

Gbr 7. Diagram alir sistem secara umum

Secara umum, sistem yang akan dibuat dapat dijelaskan oleh gambar $7 \mathrm{di}$ atas, dimana pengguna atau user akan diminta untuk melakukan inisialisasi awal untuk membuka suatau tampilan aplikasi pengendalian dengan cara mencocokan gesture yang telah ditentukan sebelumnya peintah tersebut merupakan variasi tambahan dalam pemanfaatan fitur image processing yang terdapat perangkat kinect, lalu apabila tampilan aplikasi pengendalian robot menggunkan speech recognition telah terbuka maka user dapat memberikan input berupa perintah suara yang kemudian ditangkap oleh mikrofon yang terdapat pada perangkat kinect. Setelah sinyal dari suara diubah menjadi sebuah sinyal digital, maka kemudian sinyal tersebut akan diprogram menjadi sebuah data pada perangkat lunak Visual Studio, dimana data tersebut berisikan perintah yang telah didefinisikan sebelumnya berdasarkan input perintah suara apa yang telah tertangkap, kemudian data tersebut dikirimkan dari perangkat lunak visual studio ke sebuah database webserver yang bernama firebase dengan bantuan koneksi internet. Setelah data tersebut berhasil terkirim pada database maka selanjutnya data yang terdapat pada database tersebut akan diambil alih oleh perangkat raspberry pi dengan koneksi internet yang terdapat pada robot untuk diolah lebih lanjut, dimana data perintah yang diterima akan diolah dan dieksekusi menjadi sebuah program pergerakan motor servo melalui sebuah modul SSC-32 servo controller dengan menggunakan protokol komunikasi serial. Ketika robot berhasil melakukan suatu pergerakan sesuai perintah yang masuk, maka perangkat raspberry pi akan mengirim sebuah data status ke database, yang kemudian data status tersebut akan diambil alih oleh antar muka visual studio sebagai indikator jalannya sistem.

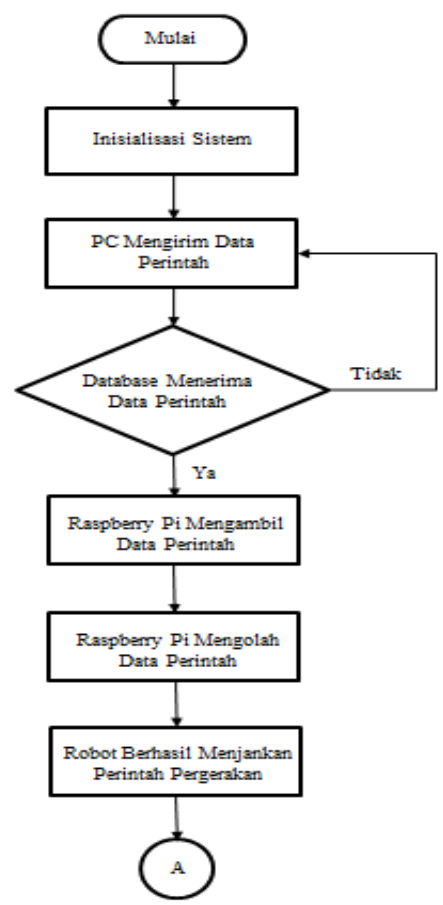

Gbr 8. Diagram alir pengiriman dan pengambilan data

Pada gambar 8. Diatas terlihat alur pemograman komunikasi untuk pengiriman dan pengambian database sebagai metode transmisi data berbasis internet dan program utama untuk pengambilan 
keputusan. Data-data yang diperoleh dari database kemudian diolah oleh masing-masing perangkat baik perangkat pengendali maupun pada perangkat robot. Pada subsistem untuk program antarmuka, yang pertama dilakukan yaitu mengatur komunikasi antara antarmuka dan database pada webserver. Kemudian jika pada perangkat pengendali dimana antarmuka dan

Page | 28 database sudah terhubung dan juga pada perangkat robot sudah terhubung maka sistem pengendalian sudah siap untuk digunakan. Setelah itu, sebagai indikasi bahwa sistem berjalan maka dilakukan proses pengiriman data status sebagai indikasi program berjalan yang kemudian ditampilkan pada antarmuka.

\section{Pemodelan Sistem}

Tahapan ini meliputi pemodelan robot humanoid dengan stick diagram dan perhitungan parameter kinematika gerak robot biped BRAT. Pada Penelitian ini, pemodelan dilakukan terhadap konstruksi model robot humannoid jenis BRAT. Sebelumnya telah dilakukan perhitungan pada model. Perhitungan ini dilakukan untuk mendapatkan karakteristik dari sistem yang akan dibuat. Secara fisik, model robot biped BRAT memiliki 3 bagian utama pada setiap kakinya, yaitu bagian pergelangan kaki (angkle), lutut (knee) dan pinggang (hip). Bagian utama tersebut dapat dilihat pada Gambar 9. dapat dibuat pemodelan berupa stick diagram untuk mempermudah perhitungan dan analisis. Pemodelan robot ini diperlukan untuk menyelesaikan permasalahan kinematika robot. Gambar 10. merupakan pemodelan dari robot BRAT yang dibuat berdasarkan kemampuan gerak robot

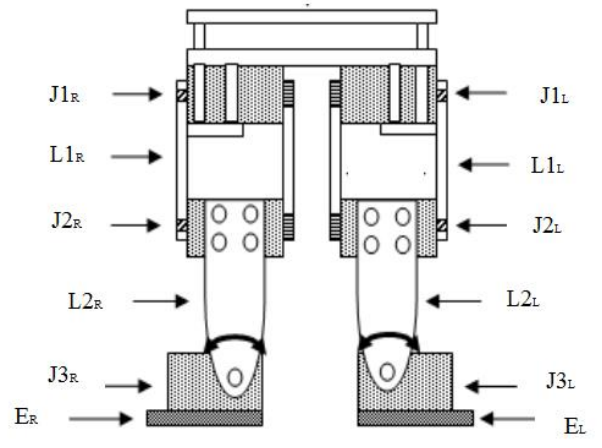

$$
\begin{array}{ll}
{ }^{*} \text { Keterangan : } & \\
\mathrm{J} 1_{\mathrm{R}}=\text { Joint } 1 \text { Kanan } & \mathrm{J} 1_{\mathrm{L}}=\text { Joint } 1 \text { Kiri } \\
\mathrm{J} 2_{\mathrm{R}}=\text { Joint } 2 \text { Kanan } & \mathrm{J} 2_{\mathrm{L}}=\text { Joint } 2 \text { Kiri } \\
\mathrm{J}_{\mathrm{R}}=\text { Joint } 3 \text { Kanan } & \mathrm{J}_{\mathrm{L}}=\text { Joint } 3 \text { Kiri } \\
\mathrm{L}_{\mathrm{R}}=\text { Link } 1 \text { Kanan } & \mathrm{L} 1_{\mathrm{L}}=\text { Link } 1 \text { Kiri } \\
\mathrm{L}_{\mathrm{R}}=\text { Link } 1 \text { Kanan } & \mathrm{L} 2_{\mathrm{L}}=\text { Link } 1 \text { Kiri } \\
\mathrm{E}_{\mathrm{R}}=\text { End Effector } 1 \text { Kanan } & \mathrm{EL}_{\mathrm{L}}=\text { End Effector } 1 \text { Kiri }
\end{array}
$$

Gbr 9. Bagian Fisik Robot Biped BRAT

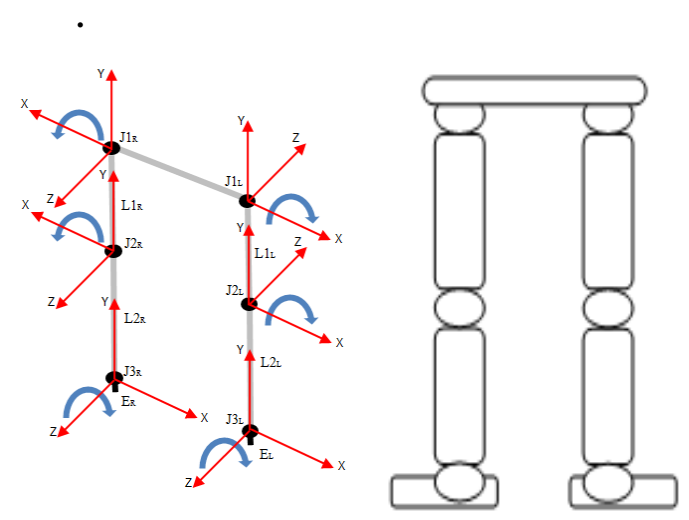

Gbr 10. Pemodelan Stick Diagram model Robot Biped BRAT

\section{Integrasi Sistem}

Tahap ini merupakan proses gabungan dari semua sistem yang juga merupakan tahapan terakhir dari proses perancangan sistem. Tiap domain ini terbentuk dari perangkat-perangkat yang telah terinstalasi pada tahapan sebelumnya. Meliputi instalasi penggabungan bagian mekanik, elektrik dan informatik. Pengujian sistem terintegrasi dan analisis hasil sistem dengan rancana sistem. Verifikasi sistem tetap dilakukan mengingat proses perancangan ini mengacu pada daftar tuntutan dan spesifikasi untuk bagian utama. Setelah proses ini dilakukan maka akan dilakukan tahap pengujian sistem secara keseluruhan sebagai perbandingan antara rencana sistem dengan aktual sistem. gambar 11.

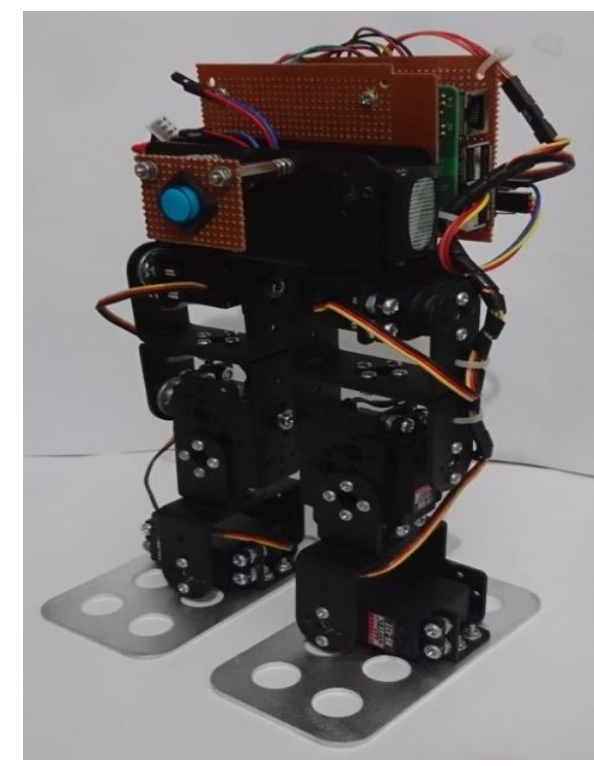

Gbr 11. Hasil Integrasi Sistem

\section{E. Verifikasi dan Validasi}

Verifikasi dan validasi sistem ilakukan dengan mengacu pada daftar tunttan dan spesifikasi yang telah ditentukan sebelumnya. Proses verifikasi dan validasi dilakukan secara terus-menerus sesuai dengan perkembangan dan kemajuan sistem. Setelah proses verifikasi dan validasi dilakukan maka akan dilakukan 
tahap pengujian sistem sebagai perbandingan antara rencana sistem sebagai acuan sistem yang diharapkan dengan aktual sistem. Sistem kendali ini menggunakan beberapa bentuk gelombang suara yang berbeda-beda sebagai masukannya, setiap gelombang suara yang diterima mewakili nilai keluaran yang berbeda-beda sehingga dapat

Page | 29 menghasilkan keluaran berupa instruksi robot biped BRAT yang berbeda-beda. Pada tahapan ini dilakukan verifikasi dan validasi mengenai rancangan dengan melakukan pengujian sistem. Apabila terdapat perubahan atau konsep rancangan yang lebih spesifik maka dilakukan proses perancangan kembali dengan tetap mengacu pada daftar spesifikasi sistem. Dalam pelaksanaannya hubungan terintegrasi secara spesifik digunakan untuk memberitahu domain masing-masing dalam perubahan suatu kondisi.

\section{HASIL DAN PEMBAHASAN}

Pada aktualnya, antara komponen pengendali seperti pengguna, mikrofon dan PC/Laptop dengan objek yang dikendalikan dalam hal ini robot, sebenarnya tidak dibatasi oleh jarak karena untuk system kerja pada pengendalian ini hanya memerlukan koneksi internet dalam mengakses perangkat satu dengan yang lainnya. Secara garis besar terdapat beberapa pengujian yang dapat kita ambil sebagai parameter dan tolak ukur sejauh mana keefektifan dan keefisienan sistem dari pada sistem yang telah kita buat, seperti pengujian penangkapan suara, pengujian sensitifitas perangkat dalam menangkap suara, kemudian pengujian respon sistem internet, serta pengujian pergerakan robot.

\section{A. Pengujian Penangkapan Suara}

Pengujian penangkapan suara dilakukan untuk mengukur seberapa efektif mikrofon dan program pengolahan sinyal suara dalam menangkap perintah suara yang diberikan. karakteristik gelombang dari tiap-tiap perintah suara yang tertangkap microphone array pada perangkat kinect yang kemudian divisualisasikan melalui visual studio, berikut contoh tampilan hasil pengujian penangkapan suara untuk perintah forward dan back terlihat pada gambar 12 dan 13.

1. Forward

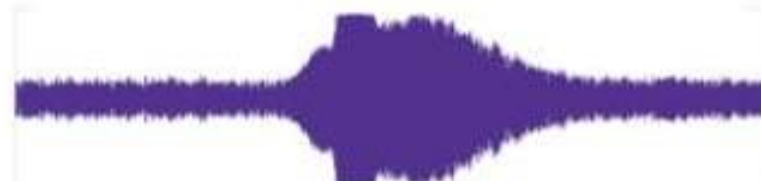

Gbr 12. Gelombang Suara pada Perintah Forward

2. Back

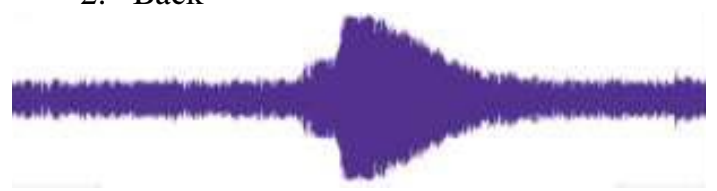

Gambar 13. Gelombang Suara pada Perintah Back

Data karakteristik gelombang perintah suara di atas dihasilkan dengan cara menangkap suara pengguna dengan mikrofon array perangkat kinect dengan bantuan aplikasi visual studio, dengan aplikasit ersebut kita dapat melihat data gelombang yang tertangkap, dimana tiap suara mempunyai karakter tersendiri baik itu kata atau berupa suara apapun yang bisa ditangkap oleh perangkat, berdasarkan Analisa pada gelombang dari suara yang tertangkap tersebut, panjang-pendek, tinggi-rendahnya suatu gelombang disebabkan karena tingkat intensitas suara dan juga karena jenis sumber bunyi, seperti bibir, lidah, serta Tenggorokan pada manusia. Seperti contoh bunyi pada pelafalan huruf A$\mathrm{Z}$, dimana mempunyai pelafalan yang berbeda-beda dan bersumber dari kombinasi gerak antara bibir, lidah atau tenggorokan. Dalam penelitian ini pengujian penangkapan suara dilakukan sebanyak 100 kali pada masingmasing perintah suara, kemudian perintah suara yang masuk akan diidentifikasi tingkat keberhasilannya serta kegagalannya, sehingga dapat diketahui faktor apa saja yang dapat mempengaruhi jalannya system pada tahap penangkapan suara tersebut. Pada table I. Terlihat hasil pengujian penangkapan suara menggunakan sensor kinect, akan dijelaskan pada tabel berikut.

TABEL I

KEBERHASILAN PERINTAH SUARA MENGGUNAKAN SENSOR KINECT HASIL

\begin{tabular}{|c|c|c|c|c|c|}
\hline \multirow[b]{2}{*}{ No. } & \multirow{2}{*}{$\begin{array}{l}\text { Perinta } \\
\text { h Suara }\end{array}$} & \multirow{2}{*}{\begin{tabular}{|c} 
Banyak \\
Percobaa \\
n
\end{tabular}} & \multicolumn{2}{|c|}{ Hasil } & \multirow[b]{2}{*}{ Error } \\
\hline & & & $\begin{array}{c}\text { Berhasi } \\
1\end{array}$ & Gagal & \\
\hline 1 & Forward & 100 & 98 & 2 & $2,00 \%$ \\
\hline 2 & Back & 100 & 97 & 3 & $3,00 \%$ \\
\hline 3 & Turn Left & 100 & 96 & 4 & $4,00 \%$ \\
\hline 4 & Turn Right & 100 & 98 & 2 & $2,00 \%$ \\
\hline 5 & Kick Left & 100 & 95 & 5 & $5,00 \%$ \\
\hline 6 & Kick Right & 100 & 98 & 2 & $2,00 \%$ \\
\hline 7 & Respect & 100 & 99 & 1 & $1,00 \%$ \\
\hline \multicolumn{3}{|c|}{ Rata-rata } & 97,29 & 2,71 & $2,71 \%$ \\
\hline
\end{tabular}

Dari tabel 1 di atas dapat disimpulkan bahwa secara keseluruhan sensor kinect memiliki akurasi sebesar 97,29\% dalam menangkap perintah suara yang diberikan. Dalam hal ini data menunjukan bahwa sensor kinect yang digunakan sebagai komponen yang memberi input dalam sistem pengendalian ini memiliki kesalahan sebesar $2,71 \%$. Nilai error tersebut disebabkan oleh beberapa masalah yaitu tidak terbacanya perintah suara, masalah tersebut bisa disebabkan karena ketidak jelasan suara, mungkin juga karena noise, atau bisa juga aplikasi pengolah data yang sedang lagging ketika perintah suara diberikan, karena kemampuan dan peran PC sangat dihandalkan dalam melakukan pengolahan data. Selain itu masalah lain yang muncul ialah salah pembacaan perintah suara, kemungkinan besar masalah ini disebabkan karena ketidak jelasan suara yang tertangkap sehingga 
menghasilkan karakter gelombang suarayang tertangkap menjadi jauh dari perintah suara yang dimaksud, malah justru lebih mendekati karakter gelombang suara dari perintah yang lainnya, sehinggaakhirnya program lebih memilih perintah suara yang karakter gelombangnya lebih mendekati karakter gelombang suara yang tidak jelas tersebut dan

Page | 30 salah pembacaanpun tidak terhindarkan. Sebagai data pembanding, untuk mengetahui bagaimana tingkat keefektifitasan sensor Kinect dalam melakukan penangkapan suara, maka dilakukan sebuah pengujian serupa terhadap perangkat lain, yaitu pada perangkat mikrofon PD346, dimana hasilnya dapat dilihat pada tabel II. berikut:

TABEL II

KEBERHASILAN PERINTAH SUARA MENGGUNAKAN MIKROFON PD346

\begin{tabular}{|c|l|c|c|c|c|}
\hline \multirow{2}{*}{ No. } & \multirow{2}{*}{$\begin{array}{l}\text { Perintah } \\
\text { Suara }\end{array}$} & \multirow{2}{*}{ Banyak } & \multicolumn{2}{|c|}{ Hasil } & \multirow{2}{*}{ Error } \\
\cline { 4 - 5 } & & & Berhail & Gagal & \\
\hline 1 & Forward & 100 & 100 & 0 & $0,00 \%$ \\
\hline 2 & Back & 100 & 100 & 0 & $0,00 \%$ \\
\hline 3 & Turn Left & 100 & 88 & 12 & $12,00 \%$ \\
\hline 4 & Turn Right & 100 & 100 & 0 & $0,00 \%$ \\
\hline 5 & Kick Left & 100 & 90 & 10 & $10,00 \%$ \\
\hline 6 & Kick Right & 100 & 100 & 0 & $0,00 \%$ \\
\hline 7 & Respect & 100 & 100 & 0 & $0,00 \%$ \\
\hline \multicolumn{7}{|c|}{ Rata-rata } & 96,86 & 3,14 & $3,14 \%$ \\
\hline
\end{tabular}

Dari tabel II. di atas dapat disimpulkan bahwa perangkat mikrofon tersebut cukup bagus dalam menangkap suara dan mempunyai error yang tidak jauh beda dengan perangkat kinect, yaitu sebesar $3,14 \%$. Namun yang menjadi perhatian pada perangkat ini ialah kesalahan pembacaan suara terhadap beberapa perintah suara tertentu seperti Turn Left dan Kick Left, dimana nilai error yang dihasilkan disebabkan oleh penangkapan suara dari kedua perintah suara ini cukup banyak dibanding perintah yang lainnya, hal ini menimbulkan kerentanan pada kinerja perangkat karena kesalahan yang terjadi terpusat pada beberapa perintah suara saja, sehingga sulit mendiagnosa masalah yang terjadi. Berbeda dengan perangkat kinect yang secara keseluruhan mempunyai permasalahan yang merata pada tiap-tiap perintah suara, sehingga sangat wajar dan pengguna bisa lebih yakin dalam mendiagnosa atau menduga masalc $\varepsilon^{*}$

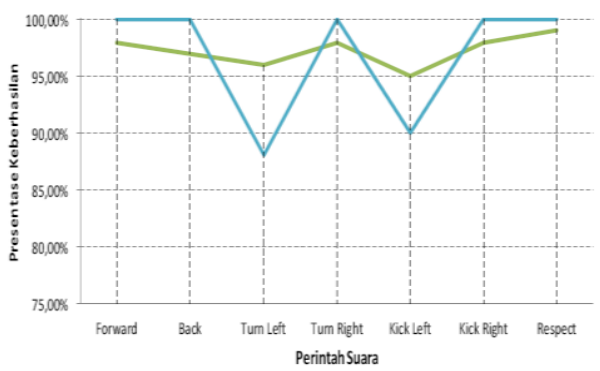

Gbr 14. Grafik Perbandingan antara Perangkat Kinect dengan Mikrofon
Dari grafik gambar 14. menjelaskan bahwa peerangkat kinect lebih konsisten permasalannya dibanding mikrofon PD346 dengan masing -masing mempunyai rata-rata kesalahan $2,71 \%$ dan $3,14 \%$ pada keseluruhan perintah suara.

\section{B. Pengujian Repon Sistem Internet}

Pengujian respon sistem internet dilakukan untuk menguji seberapa cepat sebuah perangkat dalam mengakses data. Pada penelitian ini terjadi sebuah aktivitas komunikasi antara PC dengan raspberry pi dengan sistem yang terkoneksi internet dalam melakukan pengirimaan ataupun penerimaan data, dalam hal ini data yang diolah berupa data yang tersimpan pada database firebase, diamana terdapat dua data, yaitu data perintah dan data status yang berfungsi untuk mengindikasikan berjalannya suatu sistem.Pengujian respon sistem internet tersebut dilakukan dengan cara menghitung keterlambatan atau menghitung berapa lama waktu yang dibutuhkan dalam setiap perintah yang dikirim, maka kemudian terjadi proses pengiriman data dari PC ke perangkat raspberry pi pada robot dengan perantara database online, sampai pada akhirnya robot melakukan pergerakan. Berikut tampilan pada masing-masing aplikasi yang berkaitan dalam melakukan pengujian ini, dimana aplikasi tersebut mengindikasikan berjalannya system

TABEL III

DATA PENGUJIAN RESPON SISTEM INTERNET

\begin{tabular}{|c|c|c|}
\hline $\begin{array}{c}\text { Percobaan } \\
\text { ke }\end{array}$ & Waktu yang dibutuhkan & Keterangan \\
\hline 1 & 1.3 & respon lancar \\
\hline 2 & 1.31 & respon lancar \\
\hline 3 & 1.52 & respon lancar \\
\hline 4 & 1.08 & respon lancar \\
\hline 5 & 1.55 & respon lancar \\
\hline 6 & 1.44 & respon lancar \\
\hline 7 & 1.05 & respon lancar \\
\hline 8 & 1.56 & respon lancar \\
\hline 9 & 1.04 & respon lancar \\
\hline 10 & 1.24 & respon lancar \\
\hline rata-rata & 1.39 & respon lancar \\
\hline
\end{tabular}

Berdasarkan Tabel III. data pengujian yang didapat respon sistem pada penelitian ini menunjakan bahwa sistem dapat berjalan dengan rata-rata waktu keterlambatan sebesar 1,31 detik. Dengan demikian dalam penelitian ini penggunaan sistem kerja internet yang digunakan untuk pengendalian robot dapat dikatakan bekerja secara realtime, dengan catatan bahwa area kerja pada masing-masing perangkat harus mempunyai koneksi internet yang bagus. Pada pengujian respon sistem internet terdapat catatan 
bahwa selama melakukan pengujian ini semua perangkat dalam keadaan dan memiliki akses yang sama dalam hal sinyal internet. Untuk aplikasi yang digunakan dalam melakukan pengukuran kecepatan internet selama melakukan pengujian respon yaitu menggunakan fast.com. Dimana pengecekan kecepatan internet dilakukan secara bersamaan saat

Page | 31 data dari PC dikirimkan ke database firebase untuk diambil alih oleh perangkat raspberry pi. Berikut data kecepatan internet dapat dijelaskan pada table Pengujian dilakukan untuk menguji apakah fungsionalitas sistem sudah berjalan dengan benar. Hasil pengujian memasukkan data pelatihan fonem dapat berjalan dengan benar. Dari pengujian tersebut terbukti bahwa fungsi untuk menggerakan robot dengan metode speech recognition dapat berjalan dengan benar dan akurat.

\section{Pengujian Akurasi Gerakan}

Kemudian untuk menguji tingkat akurasi gerakan robot dilakukan pengambilan data depth oleh pembacaan tiap perubahan $10 \mathrm{~cm}$. data tersebut dibandingkan dengan pembacaan penggaris yang presisi hasil ujicoba sensor kinect terllihat pada tabel IV. dibawah ini.

TABEL IV

PENGUJIAN AKURASI SENSOR

\begin{tabular}{|c|c|c|}
\hline $\begin{array}{c}\text { Jarak } \\
\text { acuan }(\mathbf{c m})\end{array}$ & Jarak sebenarnya & Error \\
\hline 70 & 72.4 & 3.3 \\
\hline 80 & 81.6 & 1.9 \\
\hline 90 & 91.9 & 2.07 \\
\hline 100 & 102.1 & 2.06 \\
\hline 200 & 202.3 & 1.1 \\
\hline 300 & 302 & 0.66 \\
\hline 400 & 402 & 0.6 \\
\hline
\end{tabular}

Dari hasil ujicoba dapat disimpulkan bahwa depth sensor pada sensor kinect cukup presisi dan akurat dengan error rata-rata pengkuran $1,69 \mathrm{~cm}$. Dalam pengukuran terlihat error terjadi lebih besar saat jarak depth sensor semakin menjauh. Dalam pengujian didapatkan bahwa deadzone $<50 \mathrm{~cm}$ dan $>4 \mathrm{~m}$. Pada area deazone depth sensor tidak dapat membaca peregerakan user.

\section{Pengujian Sensitifitas Perangkat Dalam Melakukan Penangkapan Suara}

Pengujian Sensitifitas Perangkat Dalam Melakukan Penangkapan SuaraPengujian ini dilakukan untuk mengetahui sensitifitas perangkat mikrofon dalam melakukanmpenangkapan suara berdasarkan nilai desible atau nilai intensitas suara dari perintah suara yang diberikan. Untuk mengetahui seberapa sensitif kemampuan mikrofon pada perangkat kinect dibanding perangkat lain, maka dilakukan pengujian serupa terhadap perangkat lain, yaitu pada perangkat mikrofon PD346. Pengujian dilakukan dengan cara pengguna memberikan input berupa perintah suara dengan tingkat/range intensitas yang berbeda, dimana tingkat/range tersebut dipilih pada daerah kritis dimana pendeteksian suara pada tingkat tersebut susah untuk ditangkap. Berikut penjelasan tentang pengujian senitifitas perangkat dapat dijelaskan pada tabel berikut :

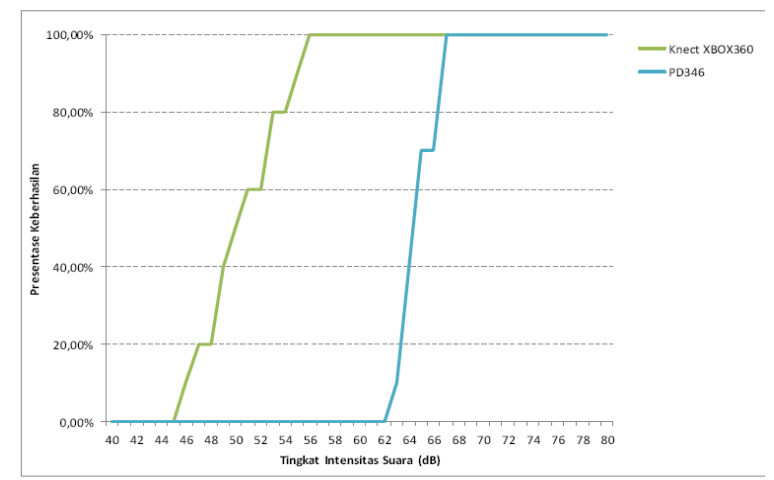

Gbr 15. Perbandingan Sensitivitas Perangkat

Pada gambar 15. terdapat grafik bahwa mikrofon yang terdapat pada perangkat kinect mampu menangkap perintah suara dengan tingkat intensitas suara mulai dari $>=46 \mathrm{~dB}$, sementara pada mikrofon PD346 dapat menangkap perintah suara pada tingkat intensitas suara mulai dari $>=63 \mathrm{~dB}$. Dengan demikian dapat dipastikan bahwa mikrofon yang terdapat pada perangat kinect lebih sensitif dibanding mikrofon PD3464.4

\section{E. Pengujian Pergerakan Robot}

Sedangkan untuk pengujian akurasi gerakan dilakukan untuk menguji apakah fungsi sistem sudah berjalan dengan benar. Hasil pengujian dilakukan dengan cara membandingkan keakuratan gerakan robot dengan hasil perhitungan di visual studio, dengan cara kita set sebuah titik target dalam suatu garis kaertesian kemudian kita tentukan step by step langkah yang akan kita input pada robot dengan begitu kita bisa membandingkan hasil perhitungan program dengan hasil aktual robot. Pengujian pergerakan robot dilakukan dengan cara membandingkan antara nilai acuan berdasarkan perhitungan kinematika dengan nilai aktual yang didapat oleh robot ketika melakukan pergerakan.

\section{KESIMPULAN}

1. Robot humanoid dapat mengikuti gerakan dan perintah suara manusia dengan bantuan perangkat Kinect sebagai sensor yang dapat menangkap suara dan gestur dari user; 
2. Robot humanoid dapat mengikuti gerakan user tanpa menggunakan kabel dengan bantuan RaspberryPi sebagai mikrokontrollernya untuk mengilangkan ketergantungan pada kabel dan server.

3. Robot humanoid dapat mengikuti gerakan manusia secara realtime dengan menggunakan firebase sebagai databasenya.

4. Rata-rata presentase pengenalan suara adalah $91,25 \%$. Ketepatan pengenalan suara paling tinggi yang didapat dari proses uji coba ini adalah kata "start" dengan nilai ketepatan 80\%. Sedangkan kata terendah adalah "stop" dengan nilai ketepatan $20 \%$.

\section{UCAPAN TERIMAKASIH}

Penulis mengucapkan terimakasih yang sebesarbesarnya kepada pihak Kemenristekdikti melalui program hibah penelitian dosen pemula yang telah memberikan bantuan dana penelitian kepada penulis dan juga rekan penelitia sehingga penelitian dapat berjalan dengan lancer dan selesai tepat waktu.

\section{DAFTAR PUSTAKA}

[1] C. Tarunajaya, O. K. Wijaya, R. L. Kuwandy, H. Ngarianto, A. A. Gunawan, and W. Budiharto, "Designing of MediumSize Humanoid Robot with Face Recognition Features," IPTEK J. Technol. Sci., vol. 26, no. 2, 2016.

[2] E. Sulistyo, "Sistem Komunikasi Robot Humanoid Dalam Aplikasi Robot Penari," Semin. Nas. Sains dan Teknol. 2015 Fak. Tek. Univ. Muhammadiyah Jakarta, no. November, pp. $1-5,2015$.

[3] T. A. S, S. Widodo, and M. Kom, "Pengendalian Robot Mobile Berbasis Web Dan Internet Protocol Melalui Jaringan Wifi," vol. 13, pp. 1-8, 2015 .

[4] W. Wang, "Humanoid Android Robot Subsystems," 2014.

[5] G. G. Maulana, Y. Erdani, A. Budiyarto, and W. Purnomo, "DESIGN AND BUILDING MOTION CAPTURE SYSTEM USING TRANSDUCER MICROSOFT KINECT TO CONTROL ROBOT," pp. 1-6.

[6] D. S. Ekasari, U. L. Yuhana, and Ri. R. Hariadi, "Rancang Bangun Modul Pengenalan Bahasa Isyarat Menggunakan Teknologi Kinect," J. Tek. Pomits, vol. 2, no. 1, pp. 1-5, 2013.

[7] B. B. I. of T. MA, W. B. J. U. XU, and S. B. J. U. WANG, "A Robot Control System Based on Gesture Recognition Using Kinect," TELKOMNIKA Indones. J. Electr. Eng., vol. 11, no. 5, pp. 2605-2611, 2013.

[8] I. J. Ding and S. K. Lin, "Performance Improvement of Kinect Software Development Kit-Constructed Speech Recognition Using a Client-Server Sensor Fusion Strategy for Smart Human-Computer Interface Control Applications," IEEE Access, vol. 5, pp. 4154-4162, 2017.

[9] W. Wanangsyah, T. Wurijanto, and T. Sutanto, "Aplikasi Virtual Punch Training Menggunakan Microsoft Xbox Kinect," Jsika, vol. 3, no. 1, pp. 94-101, 2014.

[10] A. R. Wiratno and K. Hastuti, "Implementation of Firebase Realtime Database to track BRT Trans Semarang," vol. 4, no. 2, pp. 95-103, 2017.

[11] V. Vujovic, M. Maksimović, V. Vujović, N. Davidović, V. Milošević, and B. Perišić, "Raspberry Pi as Internet of Things hardware: Performances and Constraints Raspberry $\mathrm{Pi}$ as Internet of Things hardware : Performances and Constraints," Des. Issues, vol. 3, no. JUNE, p. 8, 2014.

[12] A. Nayyar and V. Puri, "Raspberry Pi-A Small , Powerful, Cost Effective and Efficient Form Factor Computer: A Review International Journal of Advanced Research in Raspberry Pi- A Small , Powerful , Cost Effective and Efficient Form Factor Computer: A Review," no. December,
2015.

[13] B. Koyuncu and M. Güzel, "Software Development for the Kinematic Analysis of a Lynx 6 Robot Arm," Int. J. Comput. Electr. Autom. Control Inf. Eng., vol. 1, no. 6, pp. 230-235, 2007.

[14] Google Firebase, "Firebase Realtime Database," Firebase Realt. Database Guid., p. Firebase Realtime Database, 2017.

[15] P. Menggunakan and M. Continuously, "PERANCANGAN SISTEM TRANSMISI SPINDEL MESIN BUBUT PMSVARIABLE TRANSMISSION DENGAN PENDEKATAN METODE RETROFIT," no. November 2016, pp. 8-9, 2019.

[16] M. Nazri and B. Ismail, "Gesture Recognition Robot via Kinect Sensor," no. December, 2016. 